\section{Towards a biology of the mind}

\author{
Brain-Wise: Studies in \\ Neurophilosophy \\ by Patricia Smith Churchland \\ MIT Press: 2002.438 pp. $\$ 65, £ 43.50$ (hbk);

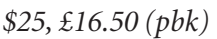

\section{Alva Noë}

The main aim of philosophy is to understand our nature and our place in the universe. In Brain-Wise, Patricia Smith Churchland provides an introduction to what she calls 'neurophilosophy' — philosophy as it is being transformed by advances in neuroscience.

The book comprises a series of essays written for the non-specialist on philosophical topics such as the self, consciousness, freedom of will, knowledge and the existence of God, and touches on learning, language and causality. Each chapter contains a survey of philosophers' arguments, and a review of relevant work in cognitive neuroscience. For example, in the chapter on the self, Churchland discusses a variety of neurobiological disorders associated with the breakdown of the self, such as parietal lesions, anorexia nervosa and the dementias. The chapter on consciousness contains an admirable critical review of work on the neural correlates of consciousness. Neuroscientists will find these discussions illuminating, and philosophers will find them informative.

The book is intended as an introductory textbook for students, but it is more than this. It is also an extended criticism of philosophy as seen from the viewpoint of neurophilosophy. Churchland seeks to establish that neuroscience is relevant to at least some philosophical problems, a claim that one might have thought didn't need establishing. This is where the book is most fascinating, but also where it is most open to criticism. The discussion turns on the status of neuroscience as science, and also on the relationship of philosophy to science in general.

Are there any philosophers who deny the relevance of brain science to philosophy? Churchland's main target seems to be those who defend the 'computer model' of the mind, which views the mind as software to the brain's hardware. According to this view, to understand the mind we must ignore the details of the way it is implemented in the brain. Churchland is right to say that the hardware-software distinction has no basis in biology. But as a criticism of the computer model, this observation lands wide of the mark.

There is not much doubt that mental function resides in the brain. The difficulty has always been understanding mental function in neural terms. Neural activity itself - at whatever scale of organization — seems to be

\title{
Exhibition
}

\section{The medicine man's museum}

Henry Wellcome is best known for his endowment of The Wellcome Trust, an influential UK research charity. But in the latter part of his life the pharmaceutical entrepreneur used his immense wealth to support his passion for collecting. He scoured the globe for artefacts relating to the history of medicine, collecting any type of object from any era.

The 700 pieces in the exhibition Medicine Man: The Forgotten Museum of Henry Wellcome, which runs from 26 June until 16 November, barely scratch the surface of this vast but little-known collection; the remaining million or so objects are scattered in museums around the world.

The two dolls shown here

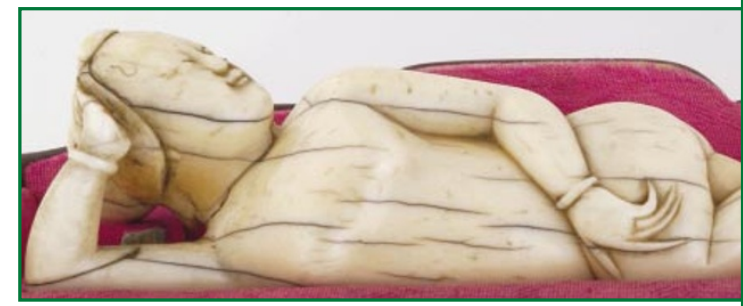

exemplify cultural differences in the attitude to the female body. The seventeenth-century ivory anatomical model (lower picture) of a pregnant woman with removable organs, probably from Germany, is thought to have been used by obstetricians and midwives to reassure pregnant women. The eighteenth-century 'diagnostic doll' from China (top) was used by women of wealthy families to indicate where their symptoms lay, as they were forbidden a physical examination by male doctors.

Other objects on display include Vincent van Gogh's only etching, L'homme a la pipe: portrait du Docteur Gachet, which is a patient's view of a doctor. Gachet, a proponent of electrical treatment for melancholia, was van Gogh's last doctor.

Alison Abbott

cognitively inscrutable. David Marr captured this idea in his book Vision (W. H. Freeman, 1982) with his remark that "trying to understand vision by studying only neurons is like trying to understand bird flight by studying only feathers: it just cannot be done."

To even begin to understand how neural events enable or constitute mental processes, those processes must be modelled in terms that are abstract in relation to neural implementation. This is certainly the dominant research strategy in cognitive neuroscience today, and one that Churchland herself uses. Consider, for example, her argument that brains use models of the effects of body movement (emulators) to enable sensorymotor coordination and offline planning of action. Is this a claim about brains as such, or is it instead about high-level cognitive architecture? It is striking that Churchland's treatment focuses, for the most part, on general engineering considerations about the utility of emulators.

One of Churchland's arguments for emulators is problematic. As a result of eye movements, the retina registers nearly continuous shifting in light patterns. How does the brain distinguish this eye-dependent change from that produced by the movement of perceived objects? Churchland's answer: "The brain undoubtedly uses emulators."
The idea is that emulators are used to keep track of, and so compensate for, eye movements. The trouble is not with the answer, but with the question, which rests on the assumption that movement of the image relative to the retina is the brain's code for movement in the environment. If we give up this assumption, there is no need for a compensatory mechanism, and hence no work for emulators to do. Emulators in the brain (at least as far as this argument shows) are merely reflections of a priori assumptions about cognitive organization.

I am not trying to call the emulator hypothesis into question. Nor do I fault Churchland for pressing the importance of developing a distinctively biological theory of mind. She is right about this. We are not there yet, however. The development of new technologies to study the brain - non-invasive imaging techniques, such as functional magnetic resonance imaging, for examplehas done little to enable us to overcome the cognitive inscrutability of neural systems. Progress in this area, as in other fields, is likely to depend on collaboration between philosophy and science. Churchland's book is a step in the right direction.

Alva Noë is in the Department of Philosophy,

University of California, Santa Cruz, California 95064, USA. 